\title{
Correction to: Mobility Under the COVID-19 Pandemic: Asymmetric Effects Across Gender and Age
}

\author{
Francesca Caselli ${ }^{1}$ (1) - Francesco Grigoli ${ }^{1}$. Damiano Sandri ${ }^{1,2}$. \\ Antonio Spilimbergo ${ }^{1,2}$
}

Published online: 5 January 2022

(c) International Monetary Fund 2022

\section{Correction to: IMF Economic Review https://doi.org/10.1057/s41308-021-00149-1}

Figure 7a has accidentally been cut in the original article and should have appeared as shown below. The updated figure fixes an error by the typesetter and restores the authors' original figure.

Francesca Caselli fcaselli@imf.org

Francesco Grigoli fgrigoli@imf.org

Damiano Sandri dsandri@imf.org

Antonio Spilimbergo aspilimbergo@imf.org

1 IMF, Washington, USA

2 CEPR, London, UK 
(a) Regression discontinuity

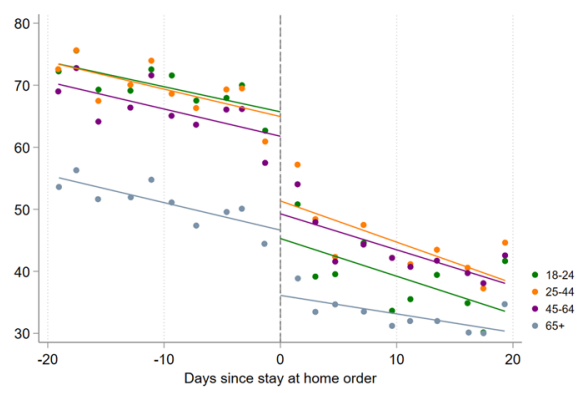

(b) Estimated impacts

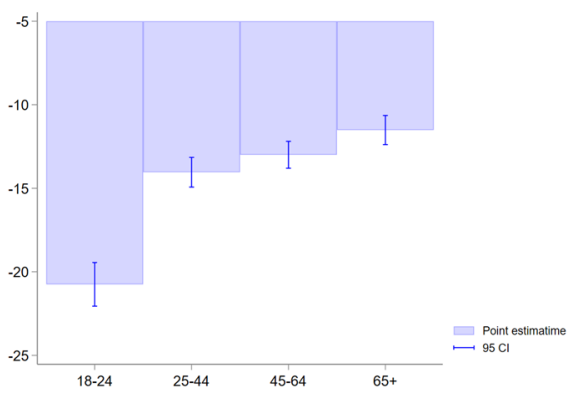

The original article has been corrected. We apologise for any inconvenience caused to our readers.

Publisher's Note Springer Nature remains neutral with regard to jurisdictional claims in published maps and institutional affiliations. 